\title{
ERBB Receptor Regulation of ESX/ELF3 Promotes Invasion in Breast Epithelial Cells
}

\author{
Jean-Philippe Coppe ${ }^{3}$, Clifton Amend ${ }^{2}$, Jeremy Semeiks ${ }^{3}$, Frederick L. Baehner ${ }^{1}$, Nora Bayani ${ }^{3}$, \\ Judith Campisi ${ }^{2,3}$, Christopher C. Benz ${ }^{1,2}$, Joe W. Gray ${ }^{1,3}$ and Richard M. Neve ${ }^{*, 1,3}$ \\ ${ }^{1}$ Cancer Research Institute, University of California San Francisco, Box 0808, San Francisco, California 94143-0808, \\ USA \\ ${ }^{2}$ Buck Institute for Age Research, 8001 Redwood Boulevard, Novato, CA 94945, USA \\ ${ }^{3}$ Lawrence Berkeley National Laboratory, Berkeley, California 94720-8268, USA
}

\begin{abstract}
ERBB2 amplification and overexpression in human breast cancer is associated with poor outcome. However, over-expression of ERBB2 alone is an early event in breast tumorigenesis, suggesting secondary events are required for progression. Here we demonstrate that the Ets transcription factor, ESX, induces an invasive phenotype in breast epithelial cells mediated through transcriptional targets of ESX. In non-transformed cells this process is regulated by EGF signaling. Expression of ERBB2 facilitates EGF-independent regulation of ESX levels, thus promoting invasion. Our data define mechanisms by which ERBB2 overexpression promotes breast cancer invasiveness and progression, and provide a model to understand the clinical behavior of this subset of human tumors and identify potential therapeutic targets to improve patient outcome.
\end{abstract}

Keywords: ESX, ELF3, epithelial, ERBB2, breast cancer.

\section{INTRODUCTION}

Ets (E26 transformation-specific) transcription factors regulate gene expression during a number of biologic processes including development, differentiation, morphogenesis, proliferation, and transformation [1]. One such protein, ESX (epithelial-restricted with serine box, also termed Elf3, Jen, Ert and Ese-1), is associated with mammary gland development, epithelial differentiation and carcinogenesis [2-8]. ESX is expressed exclusively in terminally differentiated epithelial cells in the mammary gland, colon, trachea, kidney, prostate, uterus, stomach and skin under homeostatic conditions [2, 5, 6, 8], where it regulates transcription of a number of genes $[2,3,6,7,9$ 14]. ESX is also a putative mediator of inflammatory shock and host defense responses [13, 15]. In breast cancer, ESX expression is significantly correlated with ERBB2 (erythroblastic leukemia viral onocogene homologue-b2) expression, and is a downstream transcriptional target of ERBB2 in cancer cells. ERBB2 and ESX are found at 17q12 and 1q32.1 respectively, two regions commonly amplified in breast cancer [16]. Here we investigate the functional significance of ESX and ERBB2 expression in human mammary epithelium showing that they cooperate to confer an invasive phenotype on mammary epithelial cells. Our data suggest ligand-activated EGFR receptor stabilizes ESX protein levels and the invasive phenotype. Constitutive ERBB2 signaling stabilizes ESX levels promoting invasion

*Address correspondence to this author at the Cancer Research Institute, University of California San Francisco, Box 0808, San Francisco, California 94143-0808, USA; Tel: (650)-467-4452; E-mail: neve.richard@gene.com which is independent of EGF but still requires EGFR kinase activity. We show that MMP7 and Osteopontin (SPP1) genes are regulated in response to ESX functional activation both of which are necessary but not sufficient for ESX-dependent EMT.

\section{MATERIALS AND METHODOLOGY}

\section{Cell Culture}

MCF10A cells were grown in a 1:1 mix of DMEM/Hams F12 supplemented with $20 \mathrm{ng} / \mathrm{ml}$ EGF, $100 \mathrm{ng} / \mathrm{ml}$ cholera toxin, $0.01 \mathrm{mg} / \mathrm{ml}$ insulin, $50 \mathrm{ng} / \mathrm{ml}$ hydrocortisone and $5 \%$ horse serum. All cells were grown at $37^{\circ} \mathrm{C}$ and $5 \% \mathrm{CO}_{2}$. EGF starvation experiments were performed in 1:1 mix of DMEM/Hams F12 supplemented with $100 \mathrm{ng} / \mathrm{ml}$ cholera toxin, $0.01 \mathrm{mg} / \mathrm{ml}$ insulin, $50 \mathrm{ng} / \mathrm{ml}$ hydrocortisone and $5 \%$ horse serum.

For full details of cells, growth conditions and phenotype see http://cancer.lbl.gov/breastcancer/ and reference [16].

\section{Cell Lysates}

For preparation of whole cell protein lysates, cells were washed in ice cold phosphate buffered saline (PBS) containing $1 \mathrm{mM}$ phenylmethylsulfonyl fluoride (PMSF) and then with a buffer containing $50 \mathrm{mM}$ HEPES (pH7.5), 150 $\mathrm{mM} \mathrm{NaCl}, 25 \mathrm{mM} \beta$-glycerophsphate, $25 \mathrm{mM} \mathrm{NaF}, 5 \mathrm{mM}$ EGTA, $1 \mathrm{mM}$ EDTA, $15 \mathrm{mM}$ pyrophosphate, $2 \mathrm{mM}$ sodium orthovanadate, $10 \mathrm{mM}$ sodium molybdate, leupeptin (10 $\mu \mathrm{g} / \mathrm{ml})$, aprotinin $(10 \mu \mathrm{g} / \mathrm{ml})$ and $1 \mathrm{mM}$ PMSF. Cells were extracted in the same buffer containing 1\% Nonidet-P40. Lysates were then clarified by centrifugation and frozen at - 
$80^{\circ} \mathrm{C}$. Protein concentrations were determined using the BioRad protein assay kit.

\section{Nuclear Extracts}

Cytoplasmic/nuclear fractionation was a slightly modified version of the Dignam method [Methods Enzym. $101,582-598$ (1983)]. Briefly, cells were grown on $10 \mathrm{~cm}$ plates then washed on ice with cold PBS. After PBS was aspirated, $1 \mathrm{~mL}$ of Hypotonic buffer (20mM HEPES, pH7.0, $10 \mathrm{mMKCl}, 1 \mathrm{mM} \mathrm{MgCl} 2,0.5 \mathrm{mM}$ DTT, $0.1 \%$ Triton X-100, $20 \%$ glycerol, $2 \mathrm{mM}$ PMSF, $5 \mathrm{ug} / \mathrm{mL}$ aprotinin, $5 \mathrm{ug} / \mathrm{mL}$ Leupeptin) was added, the cells were scraped and transferred to a tube on ice. The cells were then disrupted with 10-20 strokes of a Dounce Homogeniser on ice. The resulting lysate was centrifuged at $3000 \mathrm{rpm}$ for $5 \mathrm{~min}$. at $4^{\circ} \mathrm{c}$. The resulting supernatant is the cytoplasmic fraction. The pellet was resuspended in $50-100 \mathrm{uL}$ of cold extraction buffer (Hypotonic Buffer with $420 \mathrm{mM} \mathrm{NaCl}$ ). This solution was placed on a spinning wheel for $20 \mathrm{~min}$ at $4^{\circ} \mathrm{c}$ followed by centrifugation at $15000 \mathrm{rpm}$ for $10 \mathrm{~min}$ at $4^{\circ} \mathrm{c}$. The resulting supernatant contains the nuclear extract, the pellet is the insoluble nuclear matrix. Both cytoplamsmic and nuclear extract protein levels were determined and equal amounts loaded for immunologic detection.

\section{Supernatants}

$2 \times 10^{6}$ cells were seeded on to $10 \mathrm{~cm}$ plates. After $24 \mathrm{~h}$, the media was aspirated, cells washed twice in pre-warmed media without supplements, and $5 \mathrm{~mL}$ of serum-free media added to the cells with appropriate additives (4HT, EGF, depending on experimental design). At the required time points, media was removed and equivalent volumes concentrated 10-fold in Millipore centricon filters. Equal volumes were used for subsequent western analysis.

\section{Immunochemical Techniques}

For immunoblot analysis, cleared cell lysates were electrophoretically resolved on denaturing sodium doedecyl sulphate (SDS)-polyacrylamide gels (4-12\%), transferred to polyvinylidene difluoride (PVDF, Millipore), and probed with specific antisera. The following primary antibodies were utilized: anti-ESX (prepared and purified as in Chang et al. [17]), anti-CD44 (clone 2C5, R\&D systems), antiMMP7 (clone Ab-1, Oncogene), anti-SPP1 (OPN) (R\&D Systems). For immunofluorescence, cells were grown in 8well chamber slides and treated with either $1 \mu \mathrm{g} / \mathrm{ml}$ soluble ephrin-A1/Fc or Fc for $0,1,3$ or $7 \mathrm{~h}$. Cells were fixed with $4 \%$ paraformaldehyde for $30 \mathrm{~min}$ at room temperature and subsequently washed $2 \mathrm{x}$ with $\mathrm{PBS}, 2 \mathrm{x}$ with $\mathrm{PBS}+0.04 \%$ saponin and finally $2 \mathrm{x}$ with $\mathrm{PBS}+0.04 \%$ saponin $+0.03 \%$ glycine. Following $1 \mathrm{~h}$ of blocking with PBS $+20 \%$ horse serum, the cells were incubated with primary antibody for 1h. Cells were washed $4 \mathrm{x}$ in PBS $+0.04 \%$ saponin followed by a 30 min incubation in secondary antibody. Cells were visualized by fluorescence microscopy.

\section{Three Dimensional Matrigel Cultures}

Three dimensional overlay cultures were performed ass described [18]. Briefly, on ice, $35 \mu$ l of growth-factor stripped Matrigel (BD Biosciences \#356234; basement membrane analogue) was evenly distributed in each chamber of an eight-well chamber slide and allowed to solidify at $37^{\circ} \mathrm{C}$. Cells were trypsinised and resuspended to a final concentration of $1 \times 10^{5}$ cells $/ 4 \mathrm{ml}$. This was subsequently diluted 1:1 with media containing 4\% matrigel. 400 ul was added to each well. Cells were allowed to grow for several days while being monitored for growth characteristics. Fresh media containing $2 \%$ matrigel replaced expended media every $3-4 \mathrm{~d}$.

\section{RNAi Studies}

siRNA oligonucleotides were delivered to cells using the Amaxa Nucleofector System. (Amaxa Biosystem, Cologne, Germany). Briefly, $2 \times 10^{5}$ cells were resuspended in $100 \mu \mathrm{l}$ of Nucleofector ${ }^{\mathrm{TM}}$ solution, which was prewarmed to room temperature. The cells were mixed with $2 \mu \mathrm{g}$ of RNAi, transferred into an amaxa certified 96-well cuvette and transfected with program FF-130. Immediately after transfection, $500 \mu \mathrm{l}$ of the $37^{\circ} \mathrm{C}$ pre-warmed culture medium was added, and cells were plated into one well of a 6-well culture plate containing $2 \mathrm{ml}$ of pre-warmed media. After 24 $\mathrm{h}$, media was exchanged for fresh media, at which point ESXER induction started with $100 \mathrm{nM} 4 \mathrm{HT}$ if required. Western analysis of target proteins was performed $72 \mathrm{~h}$ after transfection ( $48 \mathrm{~h}$ post induction).

\section{Boyden Chamber Invasion Assay}

Assays measuring invasive potential of breast epithelial cells were performed in modified Boyden chambers with 8 $\mu \mathrm{m}$ pore filter inserts for 24-well plates (BD Biocoat \#354578), as described [19]. Filters were evenly coated with $12 \mu 1$ of ice-cold Matrigel (BD Biosciences \#356234; basement membrane analogue) diluted to $20 \%$ with ice cold PBS $(2.5 \mathrm{mg} / \mathrm{ml}$ protein), and allowed to polymerize in a humidified, $37^{\circ} \mathrm{C}$ chamber for $1 \mathrm{~h}$. Alternatively, coating with pure collagen 1 protein (BD Biosciences \#354236) diluted to $50 \%$ with ice cold PBS (1.8 $\mathrm{mg} / \mathrm{ml}$ protein) enabled to test for cell migration potential. Prior to seeding in the upper wells, cells were trypsinized, washed and spun down in serum free media, and resuspended in serum free media complemented with appropriate compounds (e.g. inhibitors). Cells $\left(75 \times 10^{3} /\right.$ well) in $200 \mu \mathrm{l}$ of serum-free media (with appropriate reagents) were added to the upper chamber, in presence or absence of $4 \mathrm{HT}$. Bottom chambers were filled with $300 \mu \mathrm{l}$ of cell culture serum-free media complemented with100 ng/ml EGF, and supplemented with $4 \mathrm{HT}$ in the appropriate samples. After $20 \mathrm{~h}$ of incubation, cells were fixed with $2.5 \%$ glutaraldehyde in PBS, and cells that had crossed were stained with May-Grünwald stain and counted. All cells and cell conditions were assayed in triplicate, and at least three independent experiments were carried out.

\section{Xenograft Studies}

Human tumor xenografts were maintained in immunecompromised mice (typically, NCR nu/nu). Tumor cells for injection were cultured under sterile conditions. The tumor cell lines were injected s.c. in single cell suspension into the flank using a $23 \mathrm{~g}$ needle/syringe. $10^{6}$ cells were injected in $200 \mu \mathrm{l}$ volume. Exogenous 4-hydroxy tamoxifen was admi- 
nistered by 60-day slow-release pellets (Innovative Research of America) implanted at the same time as the cells. Animals were monitored twice weekly until tumor nodule was palpable $(0.2-0.5 \mathrm{~cm}$ in diameter) and daily thereafter. Animals were euthanized before the tumor size exceeded $2.0-2.5 \mathrm{~cm}$ in largest diameter, or if the body condition score (BCS) is 2 or less, or body mass dropped below $85 \%$ of mass prior to cell implantation.

\section{Expression Arrays}

A total of eighteen Affymetrix microarray CEL files were analyzed, grouped into three sets of six time series experiments. The first set of six CEL files, the "C" set, contained data from ESXER-treated samples hybridized to Affymetrix GeneChip HGU133A cartridge arrays. The second set, denoted "E", contained data from ESXER-treated samples hybridized to Affymetrix U133AAofAv2 plate arrays. The third set, denoted "N", contained data from ESXERNT-treated samples hybridized to Affymetrix U133AAofAv2 plate arrays. Although the HGU133A and U133AAofAv2 are different array platforms, they both use the same HGU133A probeset series. The CEL files were preprocessed using RMA [20] with log-2 transformation in two platform-specific batches.

To obtain a list of 356 differentially-expressed probesets, we used the statistical testing capabilities of the LIMMA package for Bioconductor [21]. Both statistical significance and fold-change cutoff tests were used. To reduce technical sources of variability, each of the three sets of experiments ("C", "E", and "N") were considered a separate statistical blocks. Each of the five nonzero harvest time point replicates $(2,4,6,12$, and $24 \mathrm{~h})$ were independently compared to the zero time point replicates. Significance testing was done using LIMMA's modified t-test. We considered significant any probeset with $\mathrm{p}<=0.05$ in at least one time point contrast, after applying Benjamini-Hochberg FDR-based multiple testing correction.

Significance testing at $p<0.05$ yielded a total of 5703 significant probesets. To reduce this set, an additional foldchange cutoff was applied. First, the $\log 2$ fold changes of each probeset called significant at each of the 5 nonzero time points versus the experiment-specific zero time point were averaged across the three experiment series "C", "E", and "N", to yield five $\log 2$ fold change values for each significant probeset. Then, the 356 probesets with one or more of its five absolute $\log 2$ fold changes at least 1.5 were used for further analysis.

To classify these significantly changed probesets by their unique temporal patterns, we used the model-based clustering software MCLUST [Primary citation not in Pubmed: "Technical Report no. 415, Department of Statistics, University of Washington, October 2002". Secondary citation, where the authors apply MCLUST to microarrays, is PMID 11673243]. The 356 significantly changed probesets were clustered based on their averaged time point expression values, using the simplest possible MCLUST model, "EII", which specifies spherical clusters and no variance clustering. To determine the optimal number of clusters, we specified an initial range of clusters from 1 to 20 , then settled on 11 clusters by inspecting MCLUST's Bayesian Information Criteria (BIC) plot for each count. Significant GO terms were obtained using DAVID (http://david.abcc.ncifcrf.gov/). We generated cluster figures and tables using Bioconductor (http://www.bioconductor.org) and Java Treeview (http://jtreeview.sf.net).

\section{Cell Binding Assay}

96-well plates were coated with $100 \mu \mathrm{l}$ of $2 \mu \mathrm{g} / \mathrm{ml}$ SPP 1 overnight at $4^{\circ} \mathrm{C}$, followed by treatment with $0.5 \%$ BSA in $\mathrm{PBS}$ for $10 \mathrm{~min}$ at $37^{\circ} \mathrm{C}$ to block non-specific binding. Cells were trypsinised and resuspended (at a cell density of $5 \times 10^{4}$ ) in serum-free media containing $0.25 \%$ BSA and $100 \mu l$ of this suspension applied to the 96-well plates. The plates were incubated for $1 \mathrm{~h}$ at $37^{\circ} \mathrm{C}$, media was removed from the plates and the wells washed with twice with PBS. Cell count was measured using the Cell Titer-Glo kit (Promega). All assays were performed in triplicate and repeated at least twice.

\section{RESULTS}

\section{Inducible Expression of ESX Inhibits Cell Cycle Progression}

We generated a fusion protein containing the full length ESX protein and the ligand binding domain of the oestrogen receptor (ER) mutated for sensitivity to 4-hydroxytamoxifen (4HT) [22]. The construct (ESXER) was stably expressed by retroviral infection in MCF10A cells (MCF10A-ESXER), an ER-negative, ESX-negative [23], non-tumorigenic breast epithelial cell line [16]. Expression of the ESXER fusion protein was apparent in the cytoplasm cells after infection and selection, but undetectable in control cells (MCF10APuro) infected with an insertless retrovirus (Fig. 1a). Addition of $100 \mathrm{nM} 4 \mathrm{HT}$ to the media resulted in an accumulation of ESXER in the nuclei of treated cells as early as $1 \mathrm{~h}$ after addition (Fig. 1a) and was sustained for at least $72 \mathrm{~h}$ (not shown). ESXER protein also increased in the chromatin-bound, insoluble fraction after Dignam extraction (not shown). ESXER translocation to the nucleus resulted in a decrease in cell proliferation, as measured by cell count (Fig. 1b). Flow cytometry showed the cells accumulated in the G1 phase of the cell cycle (not shown).

\section{ESX Induces Morphological Changes but is Non- Transforming}

Induction of ESX function by $4 \mathrm{HT}$ provoked a striking morphological change in MCF10A cells. By 24h postinduction, the cells transitioned from a normal, cuboidal epithelial morphology to an elongated neural-like spindle cell morphology strongly reminiscent of an epithelialmesenchymal transition (EMT) (Fig. 1c) [24]. Functional activation of ESX was not a transforming event since MCF10A control and MCF10A-ESXER cells produced the same small number of colonies in soft agar, regardless of the presence of 4HT (not shown). In comparison, MCF10A cells expressing an oncogenic ERBB2 protein carrying an activating (oncogenic) point mutation (MCF10A-ERBB2VE) [25, 26] produced many colonies in soft agar (not shown). 
A

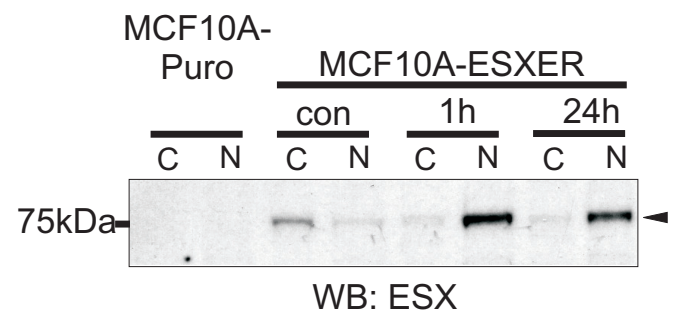

B

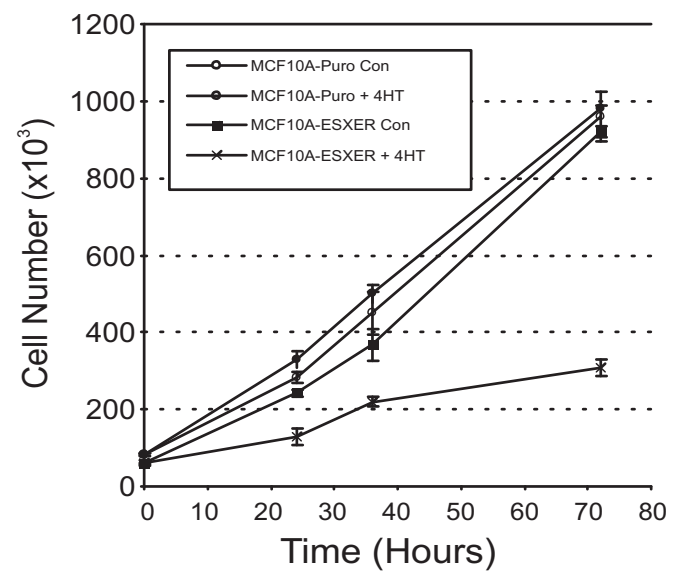

C

con

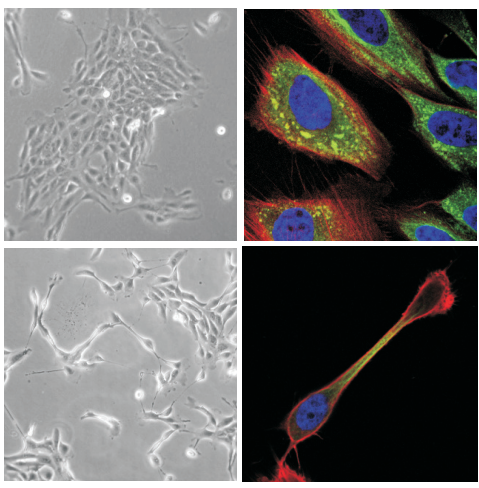

MCF10A-ESXER
D

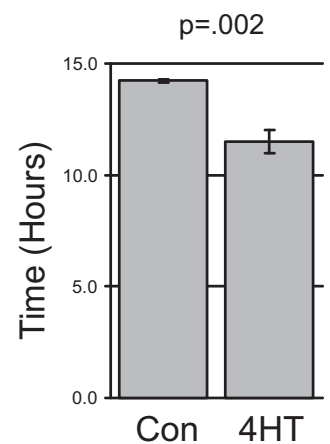

$\mathbf{E}$

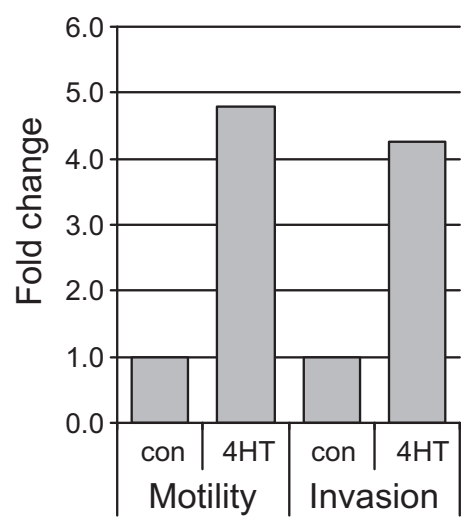

$\mathbf{F}$

MCF10A-Puro MCF10A-ESXER $24 \mathrm{~h}$
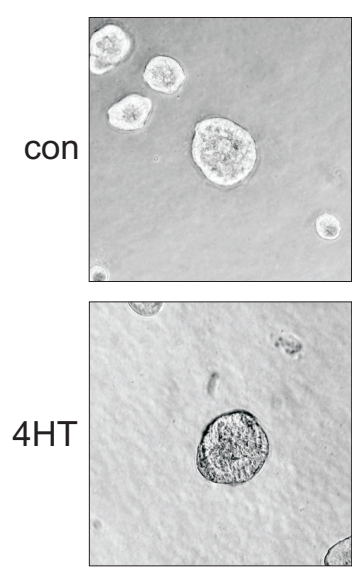
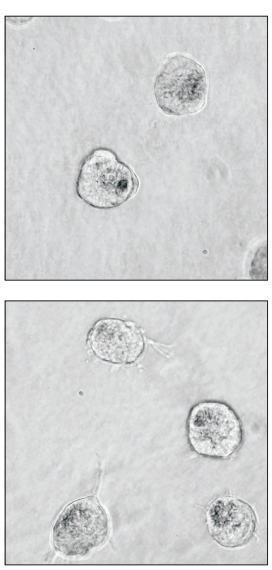

MCF10A-ESXER $48 \mathrm{~h}$
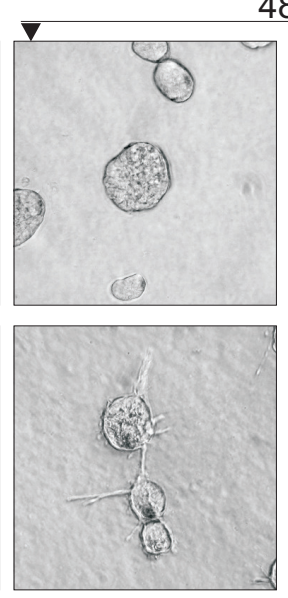
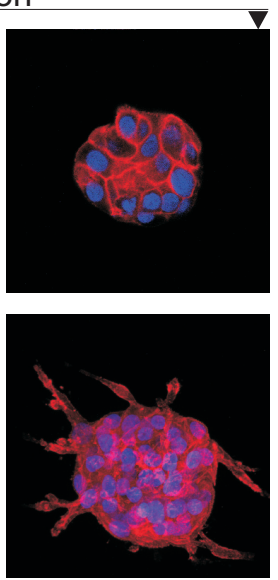

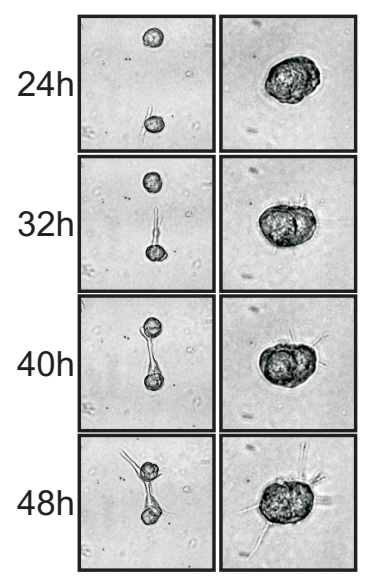

Fig. (1). Inducible ESX expression in human epithelial cells. (a) Upper panel; Detection of the ESXER fusion protein in cytoplasmic (C) and nuclear $(\mathrm{N})$ fractions of MCF10A-ESXER cells by western blotting in response to $100 \mathrm{nM} 4 \mathrm{HT}$ treatment for the indicated times. (b) Proliferation of empty vector (puro) and ESXER infected MCF10A cells in response to $100 \mathrm{nM} 4 \mathrm{HT}$ over $72 \mathrm{~h}$ as assessed by cell number. (c) Morphology of MCF10A-ESXER cells grown in the presence or absence of $100 \mathrm{nM} 4 \mathrm{HT}$ for $48 \mathrm{~h}$. Confocal image (right) colours indicate nuclei (blue), actin (red) and alpha-tubulin (yellow). (d) Scratch-cultures of MCF10A-ESXER cells in the presence or absence of $100 \mathrm{nM} 4 \mathrm{HT}$ for the indicated times. Average time to closure for several experiments are represented graphically as an average of 12 experimental replicates. (e) Changes in motility and invasion of MCF10A-ESXER cells in response to $100 \mathrm{nM} 4 \mathrm{HT}$ measured by modified Boyden chamber assays. (f) Morphology of empty vector (puro) and ESXER expressing MCF10A cells grown in 3D Matrigel drip cultures in the presence or absence of $4 \mathrm{HT}$ for the indicated times. Confocal images (right) show nuclei (blue) and actin (red). Images at stated times from two time-lapse video microscopy experiments are shown in the right hand panel. Con, control untreated cells. 4HT cells grown in presence of $100 \mathrm{nM} 4 \mathrm{HT}$. MCF10A-Puro, MCF10A cells transfected with pBabe-Puro empty vector. MCF10A-ESXER, MCF10A cells transfected with pBabe-Puro/ESXER vector. P-value calculated using Student's t-test. 
ESX Promotes Increased Motility and Invasion in Twoand Three- Dimensional Cultures

The EMT is often associated with increased cell migration and invasion [24]. Wound healing assays were employed to determine the effect of ESX on the motility of MCF10A cells. Functional activation of ESX significantly decreased the time taken for the fissure to close, as viewed by time-lapse video microscopy. Times to closure were determined for twelve independent experiments and the average depicted graphically (Fig. 1d). ESXER induction also caused cells at the leading edge to detach and move away from neighboring cells.

We next tested whether ESX changed migratory and invasive properties using modified Boyden chamber assays. Consistent with the wound healing assays, 4HT-treated MCF10A-ESXER cells showed increased migration on collagen-coated porous membranes and increased invasion through Matrigel-coated membranes (Fig. 1e). These data indicate that ESX functionally regulates both migration and invasion of mammary epithelial cells.

Three-dimensional (3D) cultures more closely reflects the properties of epithelial cells in vivo, and has been used as a tool for understanding the mechanisms of cancer progression [27]. In 3D cultures, induction of ESX caused cells to invade the Matrigel matrix compared to control cells (Fig. 1f). Time lapse video microscopy revealed that the peripheral epithelial cells of the acini gradually produced protrusions which invaded the surrounding extracellular matrix (ECM), retracted, and re-invade further in the same direction in a very dynamic process (Fig. 1f, right panel and supplemental data). The growth and retraction of these protrusions was frequently directed towards proximal acini in the culture, and migration of entire acini was a common event (Fig. 1f, right panel).

\section{ESX Function is Dependent on EGF-Signaling}

Our previous studies identified ESX as a gene regulated transcriptionally by activation of the ERBB2 receptor [17, 23]. There are four members of the type I receptor tyrosine kinase (RTK) family, with considerable crosstalk among members [28] and ERBB2 over-expression can lead to ligand-independent activation of EGFR [29]. Testing the hypothesis that ERBB2 regulation of ESX is in part mediated through EGFR we found that either removal of EGF from culture medium or treatment with the EGFRkinase inhibitor tyrphostin (AG1478) prevented the invasion and morphological changes associated with ESX activity (Fig. 2a). Similar results were achieved with two other EGFR inhibitors, IRESSA and mAb225 (Cetuximab) (not shown), suggesting that, in addition to the ERBB2 receptor, EGFR-signaling can regulate ESX-function.

To mimic ERBB2 oncogenic signaling, a point activated form of ERBB2, ERBB2VE, was expressed in MCF10A cells. ERBB2VE induced morphological changes, although the morphology was distinct from that observed after ESX induction (Fig. 2a). The effect of ERBB2VE was resistant to EGF starvation but sensitive to kinase inhibitors of EGFR, consistent with the theory of ligand-independent activation of EGFR by ERBB2 (Fig. 2a). When ESX was activated by 4HT in MCF10A-ESXER-ERBB2VE cells, long processes formed in $2 \mathrm{D}$ and $3 \mathrm{D}$, similar to the morphological changes seen in 4HT-treated MCF10A-ESXER cells. This phenotype was sensitive to AG1478 and mAb225 (not shown) but not
A

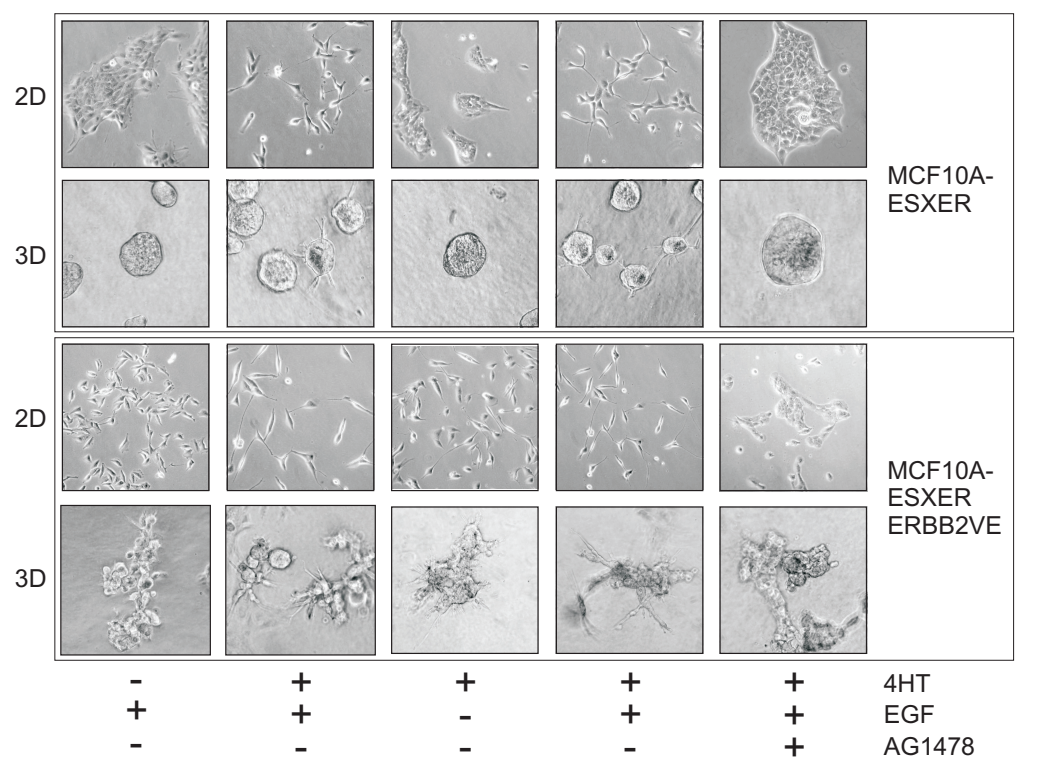

B

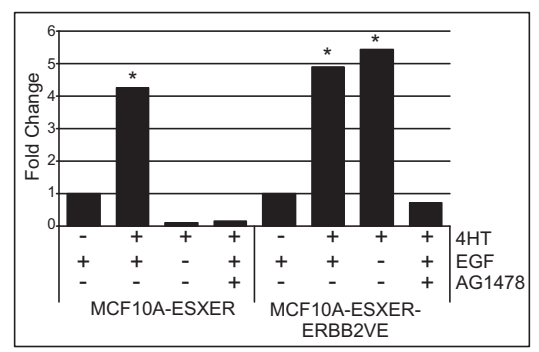

C

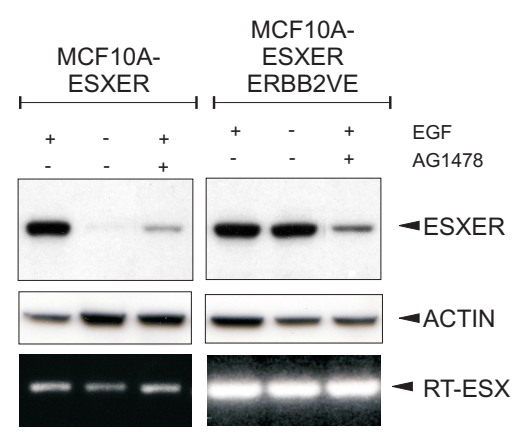

Fig. (2). EGF pathway regulates ESX-dependent EMT. (A) Effect of ESXER and/or ERBB2 expression on morphology of MCF10A cells in $2 \mathrm{D}$ and $3 \mathrm{D}$ cultures in the presence or absence of $100 \mathrm{nM} 4 \mathrm{HT}$, EGF and $10 \mu \mathrm{M}$ AG1478. (B) Invasive potential of ESXER and/or ERBB2 expressing cells in response to $100 \mathrm{nM} 4 \mathrm{HT}$ under the indicated culture conditions, as measured by modified Boyden chamber assays. Asterisk $\left(^{*}\right)$ indicates experimental condition is significantly different from control $(\mathrm{p}<=0.05)$ as calculates by a Student's t-test. (C) Effect of EGF-treatment and constitutive ERBB2 activity on the levels of ESX protein and mRNA. 
removal of EGF from the growth media (Fig. 2a) suggesting ERBB2 exerts its control over ESX at least in part through ligand-independent activation of EGFR.

ESX-dependent motility and invasion were compared between MCF10A-ESXER and MCF10A-ESXERERBB2VE cells. Induction of ESX function significantly increased both motility (not shown) and invasion (Fig. 2b). Consistent with the observed 3D morphologies, the invasive potential of MCF10A-ESXER cells was EGF-ligand and EGFR-kinase dependent. As seen with the morphological experiments, ERBB2 activity facilitated invasion in an EGFindependent manner (Fig. 2b).

We next assessed how EGFR-signaling regulates ESX protein levels and thus function. We have shown ESX transcription is regulated by ERBB signaling [23], but, in MCF10A-ESXER cells, ESXER expression is driven by a retroviral promoter which should not respond to ERBB signaling. Therefore we surmised that EGFR signaling might regulate ESX function by altering its posttranslational state or protein levels. To test this possibility, we inhibited EGFR signaling either by EGF starvation or EGFR kinase inhibition in MCF10A-ESXER cells. These manipulations resulted in a dramatic reduction in ESX protein levels (Fig. 2c, upper panels). As expected, ESX transcript levels showed no change in response to loss of EGFR signaling, indicating post-transcriptional mechanisms were responsible for the changes in protein levels. In the presence of ERBB2VE, ESX levels were still sensitive to EGFR kinase inhibition, but became insensitive to EGF starvation (Fig. 2c, lower panels). We conclude that EGFR signaling regulates ESX protein levels at least in part by post-transcriptional mechanisms.

\section{ESX Decreases Growth but Promotes Invasion of Breast Tumors}

Mouse xenografts were used to address the in vivo significance of ESX expression in ERBB2-overexpressing tumors. Cells were implanted subcutaneously and tumor growth followed in the presence or absence of slow release 4HT pellets. Consistent with the soft agar colony formation assays, neither MCF10A nor MCF10A-ESXER cells formed tumors in vivo, regardless of the presence of 4HT. MCF10AERBB2VE cells formed tumors that grew at a rate independent of the presence of 4HT (not shown). In contrast, MCF10A-ESXER-ERBB2VE cells exhibited similar growth rates to those of MCF10A-ERBB2VE cells in the absence of 4HT; however, in the presence of 4HT, growth was severely impaired and fewer tumors formed (Fig. 3a).

4HT had no effect on the pathology of tumors formed by MCF10A-ERBB2VE cells. These tumors contained cohe-
A
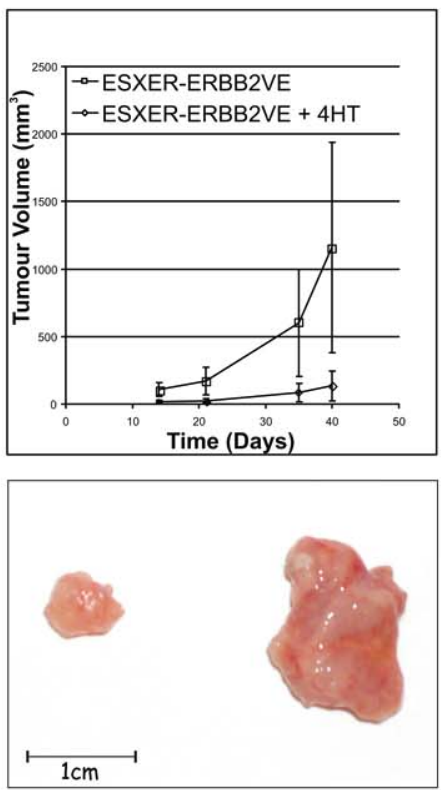

- $4 \mathrm{HT}$
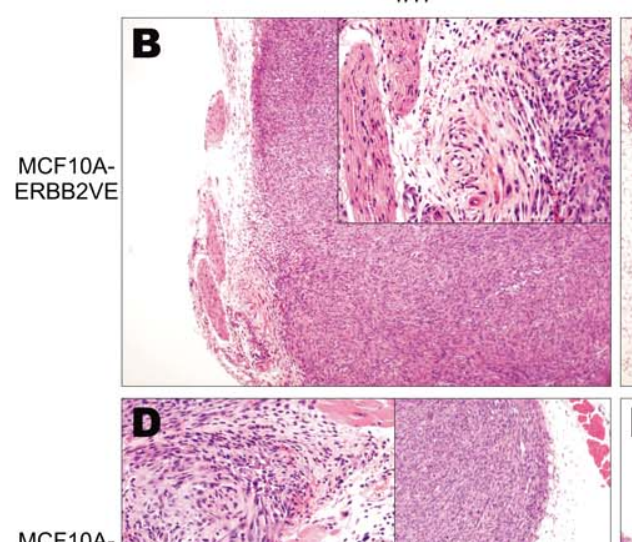

ESXER ERBB2VE
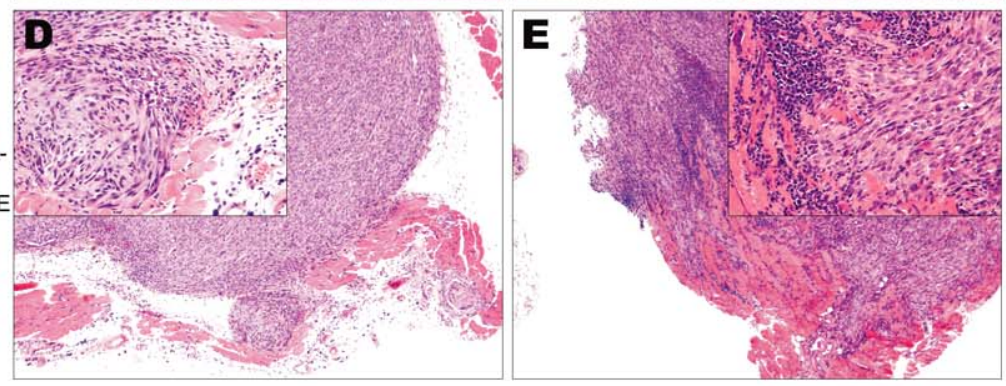

$+4 \mathrm{HT}$

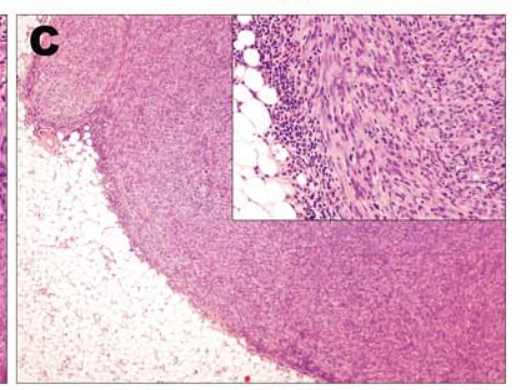
政 
sive, epitheloid cells and had smooth, pushing margins (Fig. 3b and 3c). Tumors formed by MCF10A-ESXER-ERBB2 cells in the absence of 4HT contained cohesive spindled cells and also had smooth, pushing margins (Fig. 3d). In the presence of $4 \mathrm{HT}$, however, tumors formed by MCF10AESXER-ERBB2 cells contained cohesive spindled cells but had infiltrative margins with destructive invasion of the underlying skeletal muscle (Fig. 3e). At the infiltrative tumor margin, dense inflammatory infiltrate and cohesive, spindled tumor cells were clearly visible at high power, and infiltration of small neurites and skeletal muscle was commonly observed (Fig. 3g-h). Twelve weeks after implantation, no visible metastases to the lung or liver were observed. These data support our cell culture observations, and suggest that cooperation between ESX and ERBB2 may initiate early stages of invasive breast disease.

\section{ESX-Transcriptional Profile}

To begin to identify the molecular mechanism responsible for the ESX-dependent EMT, we performed gene expression profiling of cells before and after ESX induction. Analysis of changes in gene expression measured by Affymetrix U133A arrays is shown in Fig. (4). We applied

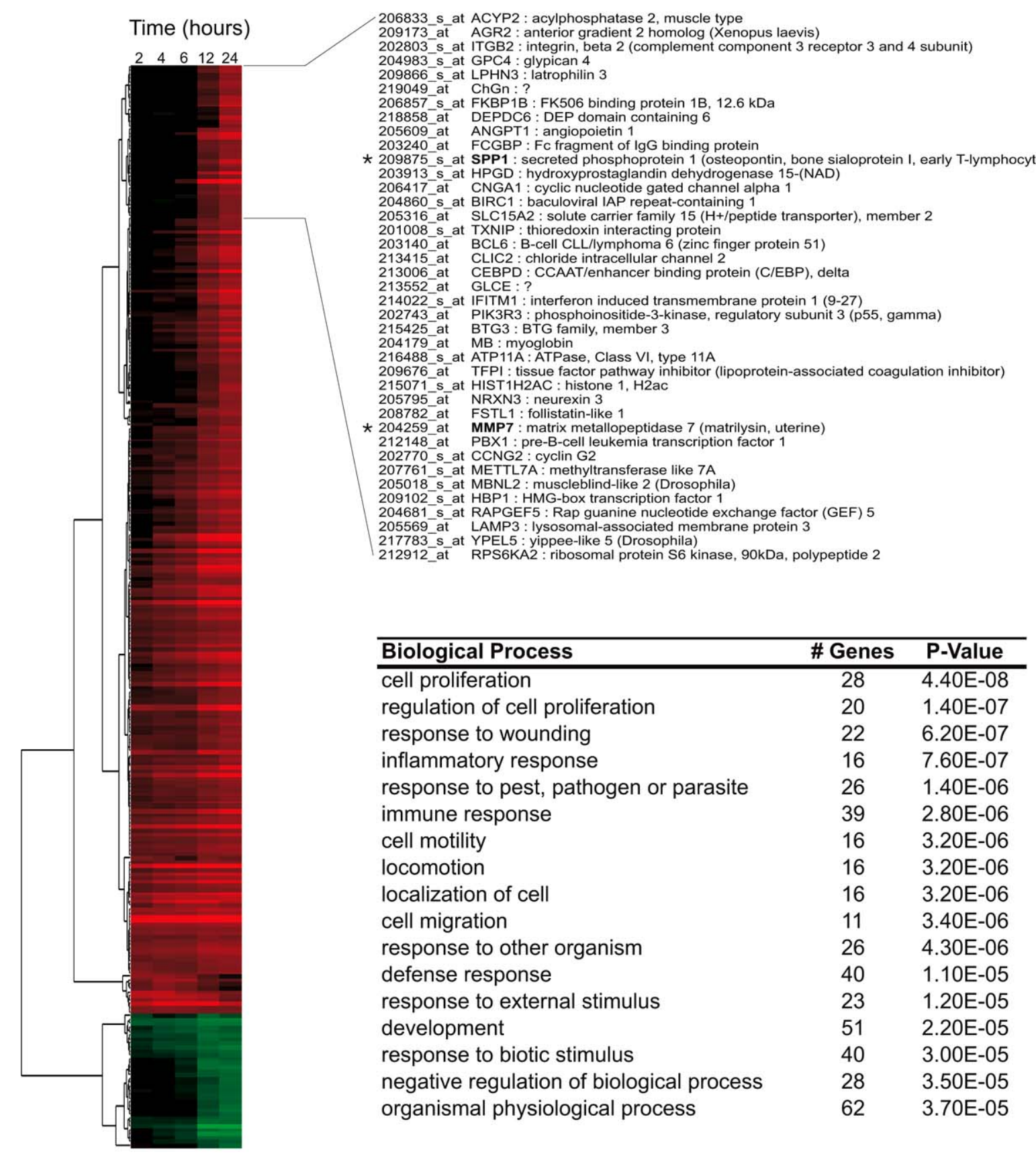

Fig. (4). Transcriptional profiling of ESX-responsive genes. Hierarchical clustering of the 356 probesets (292 unique genes) that showed significant $(\mathrm{p}<0.05)$ changes in gene expression at one or more time points $(2,4,6,12$ and $24 \mathrm{~h}$ after $4 \mathrm{HT}$ addition, relative to $0 \mathrm{~h}$ control). Expanded gene list shows cluster in which MMP7 and SPP1 are found (*). Gene Ontology (GO) terms identified several biologic processes associated with ESX-regulated genes (table). 
the modified t-test function of the LIMMA [30] software package to identify significant changes over time, revealing 356 probesets (292 unique genes) that were significant at $p$ $<0.05$.

A survey of the Gene Ontology (GO) terms identified several biologic processes that were significantly associated with ESX-regulated genes (Fig. 4). Processes such as "regulation of cell proliferation" and "cell motility" were consistent with the phenotypic changes we observed in culture (Fig. 1) and ESX has been previously implicated as mediator of inflammatory responses [31] and development [2]. The implied involvement in wound healing is a new potential function of ESX, consistent with its ability to regulate cell motility and its pattern of expression in the skin $[2,8]$.

Amongst the ESX-target genes associated with regulating cell motility and invasion, several key regulators of EMT were identified: upregulation of TWIST [32, 33], MMP7 (Matrilysin) [34], and SPP1 (Osteopontin, OPN) [35]. Parenthetically, several genes showed expression changes inconsistent with EMT, for example SNAI2 and FN1 were down-regulated. Another hallmark of EMT is loss of Ecadherin (CDH1). We found no change in CDH1 mRNA levels. We therefore examined cells for post-transcriptional changes known to regulate $\mathrm{CDH} 1$ function such as receptor clipping [36] and re-localization [37]. Western analysis of the protein in conditioned media showed that CDH1 shedding remained unchanged following ESX induction, but a significant portion of $\mathrm{CDH} 1$ relocalised to the cytoplasm (Suppl. Fig. 1).

\section{Mechanism of ESX-Dependent Invasion}

Two genes were of particular interest as potential mediators of ESX-induced invasion: MMP7 and SPP1 [38, 39]. Both proteins are associated with cancer and metastasis [40, 41], are reported transcriptional targets of Ets factors [38, 42], also SPP1 is a reported substrate of MMP7 [39]. In agreement with the transcriptional profiling, we found SPP1 and MMP7 protein were upregulated in a time-dependent manner by ESX in 2- and 3-D cultures (Fig. 5a).

Neither MCF10A nor MCF10A-ERBB2VE cells expressed either SPP1 or MMP7 in the absence or presence of 4HT (not shown). Both gene products were expressed intracellularly and secreted into the media in ESXER-expressing cell lines upon addition of 4HT (Fig. 5b). Consistent with our observed regulation of ESX levels and the invasive phenotype, culturing 4HT-treated MCF10A-ESXER cells in EGF-free media, or treatment with AG1478, decreased both SPP1 and MMP7 expression, as well as secretion of the proteins into the media (Fig. 5b), whereas ERBB2VE expressing cells retained SPP1 and MMP7 expression under EGF-starved conditions, but lost expression when treated with AG1478.

RNAi targeting of MMP7 indicated MMP7 expression is required for ESX-dependent invasion. A $>70 \%$ knock-down of MMP7 expression was achieved with two different siRNAs, reducing the level of secreted MMP7 in the media (Fig. 5c, upper panels). Reduction of MMP7 inhibited the ESX-dependent EMT as measured by morphology (not shown) and invasion/motility assays (Fig. 5d). However, expression of MMP7 alone in MCF10A produced cells morphologically indistinguishable from wild-type cells in 2 D and 3D (Suppl Fig. 2). We performed equivalent experiments targeting SPP1 expression. Similar to the effects of reducing MMP7 expression, reduced SPP1 expression decreased ESX-dependent invasion (Fig. 5d). Expression of SPP1 alone or in combination with MMP7 in MCF10A cells did not induce invasion in these cells (Suppl. Fig. 2).

MMP7 has been shown to cleave SSP1 in vitro [39]. Comparison of the pattern of cleaved SPP1 secreted into the media of ESXER-induced cells with SPP1 fragments cleaved in vitro revealed similar patterns (Fig. 5e). Reduction of MMP7 expression by RNAi markedly reduced the level of cleaved SPP1 fragments released by cells, confirming that MMP7 is required for SPP1 processing.

The pro-migratory function of SPP1 has been shown to be mediated by engaging CD44 and beta-1 integrin (ITGB1) [43]. ESX-dependent invasion was completely inhibited by treating cells with either a CD44-blocking or ITGB1-blocking antibody (Fig. 5f). Blocking the integrin-binding RGD sequence of SPP1 with peptides also inhibited ESXdependent invasion, and blocking of CD44 prevented the binding of MCF10A-ESXER cells to immobilized cleaved or uncleaved SPP1 (Fig. 5g). Together these data suggest MMP7 and SPP1 are essential but not sufficient to mediate ESX-dependent invasion in a process requiring CD44 and ITGB1 receptors (Fig. 6).

\section{DISCUSSION}

The ERBB2-oncogene is an important biomarker and therapeutic target in breast cancer. Tumors over-expressing ERBB2 have a poor prognosis, yet the conundrum exists that over-expression of ERBB2 is an early event in carcinogenesis. This raises the hypothesis that secondary events are required to promote the progression from in situ to invasive cancers. Based on our previous findings, we tested whether the Ets transcription factor ESX/ELF3 co-operates with ERBB2 to regulate tumor progression and thus identify possible alternative therapeutic targets for ERBB2-positive tumors.

We describe here an inducible system to analyze the molecular targets of the Ets transcription factor, ESX, and the biological phenotypes resulting from ESX activity. ESX has been reported to be a transforming oncogene which causes an EMT in MCF12Aa cells [44, 45]. Interestingly, the transforming ability of ESX was attributed to activities in the cytoplasm [45]. We were unable to express ESX in a number of cells lines, probably due to the anti-proliferative effect we observed in these studies. Therefore we developed an inducible system to understand ESX biology. Fusion of a mutated (4-HT sensitive) estrogen receptor ligand binding domain to a target protein is an established technique to create a inducible system to study its nuclear function. This technique provided us with a clean system to dissect the transcriptional effects of ESX in human mammary epithelial cells.

In agreement with published data, we found ESX induced an invasive phenotype, consistent with an epithelial-mesenchymal transition [24, 46]. In parallel with this effect, cell proliferation decreased, with no evidence of transformation, 
A

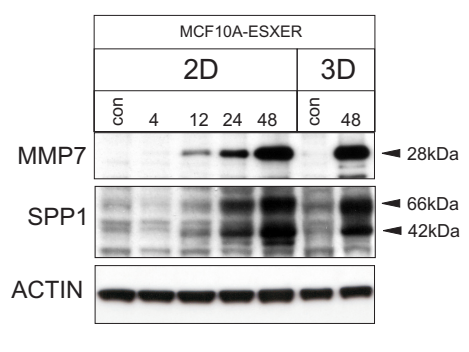

D

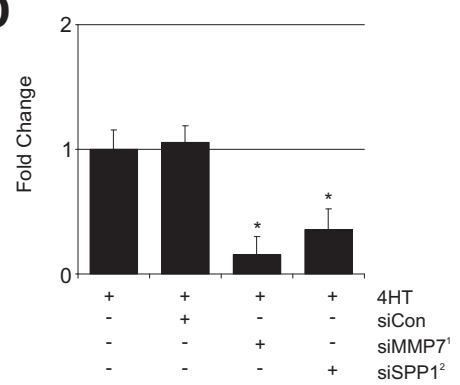

E

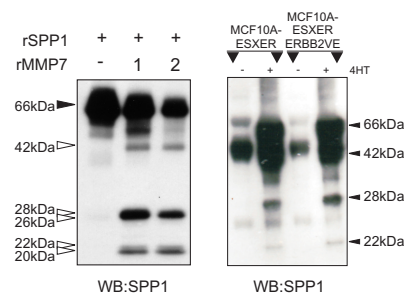

B

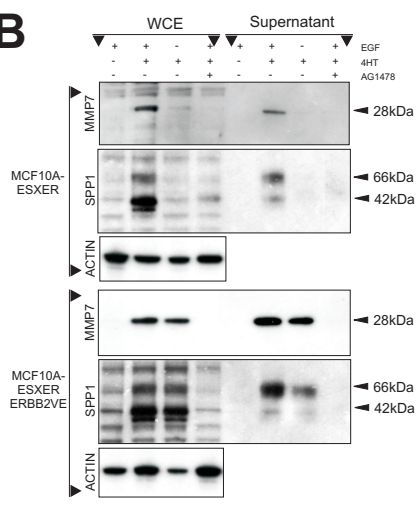

$\mathbf{F}$
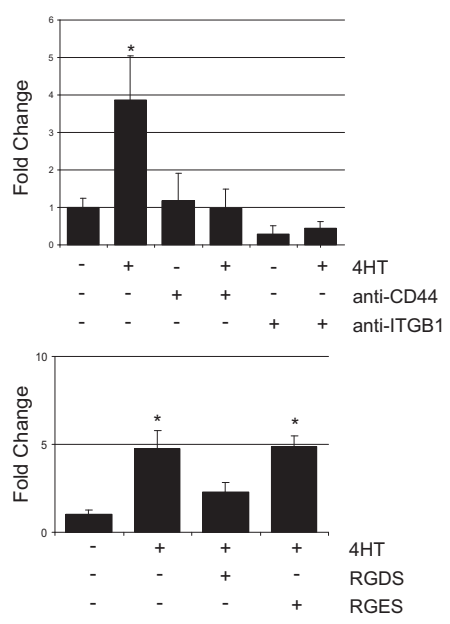
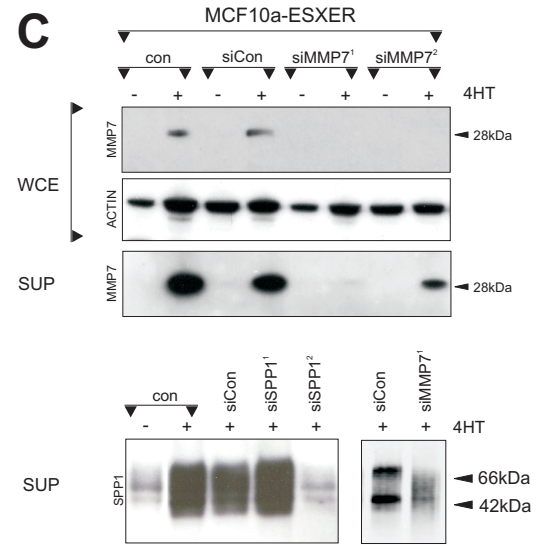

G

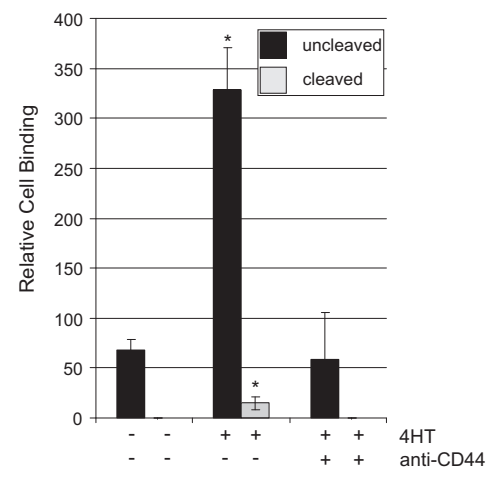

Fig. (5). Mechanism of ESX-dependent EMT. (a) Expression of MMP7 and SPP1 in 2D and 3D cultures of MCF10-ESXER cells in the presence of $100 \mathrm{nM} 4 \mathrm{HT}$ for the indicated times (in hours). (b) Expression of MMP7 and SPP1 in soluble cell extracts and supernatant of the indicated cells lines after $24 \mathrm{~h}$ treatment with $100 \mathrm{nM}$ 4HT. (c) Detection of MMP7 and SPP1 by western blotting in soluble cell extract and conditioned medium of MCF10A-ESXER treated with siRNA as indicated. (d) Effect of targeted knockdown of MMP7 or SPP1 by siRNA on invasion of ESXER-expressing MCF10A cells. Invasion represented by fold change over control 4HT treated cells. (e) SPP1 cleavage products in a recombinant MMP7-SPP1 cleavage assay (left panel) and in the supernatant of ESXER-expressing cells in the presence or absence of 4HT (right panel), as detected by western blotting. (f) Effect on MCF10A-ESXER invasion by antibody-mediated inhibition of CD44 or integrin-beta-1 (ITGB1) function (upper panel), or blocking the RGD-cell-binding domain of SPP1 (lower panel). (g) Effect of inhibiting CD44 function on cell binding to full-length and cleaved SPP1. Con, control untreated cells. WCE, whole cell extract. rMMP7, recombinant MMP7; rSPP1, recombinant SPP1. Asterisk $\left(^{*}\right)$ indicates experimental condition is significantly different from control $(\mathrm{p}<=0.05)$ as calculates by a Student's t-test.

while both migration and invasion were stimulated. Loss of E-cadherin-dependent adhesion is an essential element of the EMT. Transcription factors such as SNAI1 and SNAI2, which induced an EMT, transcriptionally repress E-cadherin expression [47]. In contrast, ESX appears to function by causing a loss of cell -surface-associated E-cadherin, resulting in an accumulation in the cytoplasm, a process seen in other cell systems and whose mechanism is still unclear [48].

A number of genes regulated in response to ESX are functionally associated with motility and/or invasion (Fig. 4). Two transcripts were of particular interest from this perspective. First, the protease MMP7 was previously described as a target of another Ets factor, and second, the secreted phosphoprotein SPP1, has been associated with invasion and poor prognosis in cancer patients. SPP1 is a reported substrate of MMP7 and cleavage of SPP1 mediates cell migration. Our data confirmed that MMP7 cleaves SPP1, that both MMP7 and SPP1 are necessary but not sufficient for ESX-dependent invasion (Suppl. Fig. 2), and that SPP1 mediates invasion at least in part through the CD44 and ITGB1 receptors. While it still remains to be seen whether SPP1 and MMP7 are direct transcriptional targets of ESX, we clearly show ESX is capable of initiating a complex network of events which stimulates EMT in breast epithelial cells (Fig. 6).

We found that expression of MMP7 in conjunction with SPP1 failed to induce an ESX-like phenotype (Suppl. Fig. 2). Indeed this is not surprising since motility/invasion is a dynamic process of attachment and reattachment and thus may be dependent on temporal-spatial patterning of gene expression not achievable through constitutive ectopic expression of these genes [49]. This implies that ESX may 


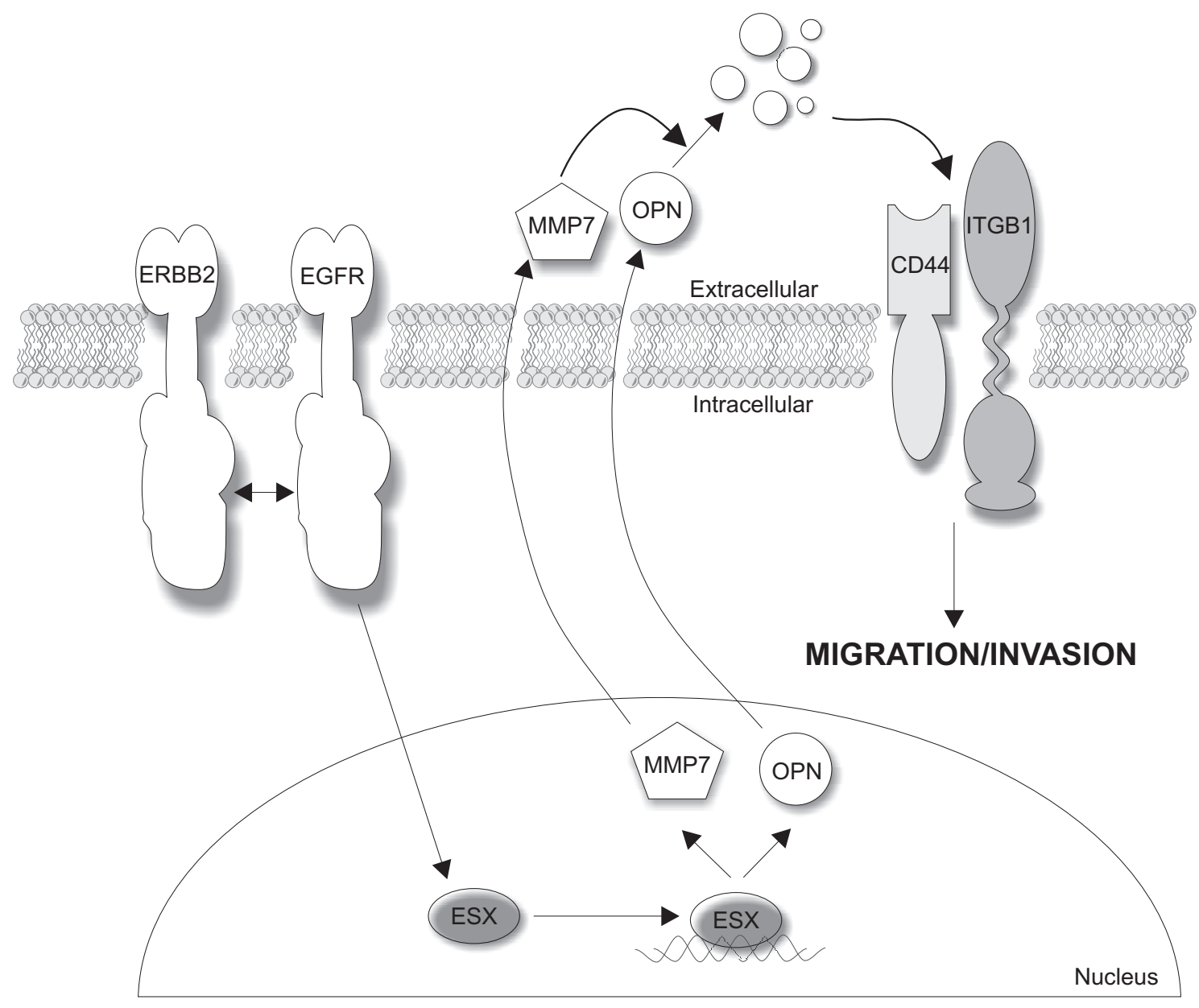

Fig. (6). Model for ESX-dependent EMT in breast epithelial cells. ESX induces (directly or indirectly) expression of MMP7 and SPP1, which are secreted into the extracellular space where MMP7 participates in the cleavage of SPP1. SPP1 is required for cellular invasion mediated through CD44 and integrin-beta-1. This process is regulated by EGFR kinase activity, through increased levels of ESX protein and thus ESX function. The oncogene, ERBB2, overcomes dependency for EGF ligand but not EGFR kinase activity. This model provides one possible mechanism through which ERBB2 over-expression in breast cancer can lead to progression and metastasis.

be a "master regulator of gene expression" for cellular invasion, similar to other transcription factors [33] and that other ESX-transcriptional target genes may be involved. Possibilities include the SERPIN protease inhibitors, several of which are upregulated in response to ESX and may regulate proteolytic cleavage of CD44 [49], and the transcription factor TWIST [33].

Our previous work showed a relationship between ERBB2 and ESX expression in human tumors. ERBB2 overexpression is an early event in human breast tumorigenesis and indicative of poor prognosis. However, overexpression of ERBB2 in non-transformed breast epithelial cells induces proliferation, but motility and invasion is unaffected or even slightly suppressed. Here we showed ERBB2 overexpression switched ESX function from ligand (EGF)-dependent to ligand-independent most likely through its transactivation of the EGF receptor kinase. Therefore, a model of progression wherein ERBB2 amplification is followed by or results in ESX expression could explain how ERBB2 expression leads to a poor prognosis in a subset of patients (Fig. 6). Importantly, ESX protein levels were stabilized by ERBB2 in
EGF-starved conditions, but remained sensitive to inhibition of EGFR-kinase activity, implying that ERBB2 exerts this effect through EGFR. The clinical ramifications of this are that EGFR-targeted therapeutics could improve outcome in ERBB2-positive tumors, a fact supported by the clinical success of the EGFR/ERBB2 specific kinase inhibitor Lapatinib in tumors refractory to ERBB2-targeted monotherapy [50]. Other potential targets include CD44 and ITGB1.

The ability of ESX to promote invasion is consistent with previous reports linking Ets factors such as PDEF, Ets 1 and Ets2 with invasive phenotypes [1]. Studies have shown overexpression of Ets factors in breast tumors. Therefore it is conceivable that ERBB2 may cooperate with different Ets factors in different breast tumor sub-types. In support of this idea, both SPP1 and MMP7, are known transcriptional targets of other Ets factors $[38,51]$. However the degree of commonality between Ets-driven transcriptomes remains to be elucidated.

Our data indicate that ESX functions to positively regulate invasion and negatively regulate cell proliferation 
both in vitro and in vivo. This negative effect on tumor growth appears counter-intuitive for successful selection of tumor cells; however, huge up-regulation of proliferation can also be counter-productive to tumor development, causing cell death or senescence [52]. Therefore, the interaction between ERBB2 and ESX may promote the growth of a subclass of tumors with slow growth but high invasive potential. Clinically these occult tumors could metastasize long before current technologies detect them.

In sum we have presented a complex signaling pathway regulating the EMT in response to ESX-dependent transcription. This is tightly controlled by EGFR signaling in normal breast epithelial cells, and deregulated by ERBB2 overexpression in cancer. Our results provide insights into cancer progression and provide several potential targets for therapeutic strategies aimed at preventing metastatic breast cancer.

\section{DISCLAIMER}

http://www.library.lbl.gov/public/tmRco/howto/RcoBerk eleyLabDisclaimer.htm. This document was prepared as an account of work sponsored by the United States Government. While this document is believed to contain correct information, neither the United States Government nor any agency thereof, nor The Regents of the University of California, nor any of their employees, makes any warranty, express or implied, or assumes any legal responsibility for the accuracy, completeness, or usefulness of any information, apparatus, product, or process disclosed, or represents that its use would not infringe privately owned rights. Reference herein to any specific commercial product, process, or service by its trade name, trademark, manufacturer, or otherwise, does not necessarily constitute or imply its endorsement, recommendation, or favoring by the United States Government or any agency thereof, or The Regents of the University of California. The views and opinions of authors expressed herein do not necessarily state or reflect those of the United States Government or any agency thereof, or The Regents of the University of California.

Ernest Orlando Lawrence Berkeley National Laboratory is an equal opportunity employer.

\section{ACKNOWLEDGEMENTS}

This work was supported by the U.S. Department of Energy, Office of Science, Office of Biological and Environmental Research (Contract DE-AC03-76SF00098), the California Breast Cancer Research Program (CBCRP) grant \# 7FB-0027, the National Institutes of Health grant \#AG09909, and the Expedition Inspiration Fund for Breast Cancer, Outstanding Young Researcher Award.

\section{CONFLICT OF INTEREST}

RMN is an employee of Genentech.

\section{SUPPLEMENTARY MATERIAL}

Supplementary material is available on the publishers Web site along with the published article.

\section{REFERENCES}

[1] Sharrocks AD. The ETS-domain transcription factor family. Nat Rev Mol Cell Biol 2001; 2: 827-37.

[2] Andreoli JM, Jang SI, Chung E, Coticchia CM, Steinert PM, Markova NG. The expression of a novel, epithelium-specific ets transcription factor is restricted to the most differentiated layers in the epidermis. Nucleic Acids Res 1997; 25: 4287-95.

[3] Brembeck FH, Opitz OG, Libermann TA, Rustgi AK. Dual function of the epithelial specific ets transcription factor, ELF3, in modulating differentiation. Oncogene 2000; 19: 1941-9.

[4] Chang CH, Scott GK, Baldwin MA, Benz CC. Exon 4-encoded acidic domain in the epithelium-restricted Ets factor, ESX, confers potent transactivating capacity and binds to TATA-binding protein (TBP). Oncogene 1999; 18: 3682-95.

[5] Neve R, Chang CH, Scott GK, et al. The epithelium-specific ets transcription factor ESX is associated with mammary gland development and involution. FASEB J 1998; 12: 1541-50.

[6] Oettgen P, Alani RM, Barcinski MA, et al. Isolation and characterization of a novel epithelium-specific transcription factor, ESE1, a member of the ets family. Mol Cell Biol 1997; 17: 4419-33.

[7] Yoshida N, Yoshida S, Araie M, Handa H, Nabeshima Y. Ets family transcription factor ESE-1 is expressed in corneal epithelial cells and is involved in their differentiation. Mech Dev 2000; 97 : 27-34.

[8] Tymms MJ, Ng AY, Thomas RS, et al. A novel epithelialexpressed ETS gene, ELF3: human and murine cDNA sequences, murine genomic organization, human mapping to $1 \mathrm{q} 32.2$ and expression in tissues and cancer. Oncogene 1997; 15: 2449-62.

[9] Choi SG, Yi Y, Kim YS, et al. A novel ets-related transcription factor, ERT/ESX/ESE-1, regulates expression of the transforming growth factor-beta type II receptor. J Biol Chem 1998; 273: 110-7.

[10] Oettgen P, Kas K, Dube A, et al. Characterization of ESE-2, a novel ESE-1-related Ets transcription factor that is restricted to glandular epithelium and differentiated keratinocytes. J Biol Chem 1999; 274: 29439-52.

[11] Reddy SP, Vuong H, Adiseshaiah P. Interplay between proximal and distal promoter elements is required for squamous differentiation marker induction in the bronchial epithelium: role for ESE-1, Sp1, and AP-1 proteins. J Biol Chem 2003; 278: 2137887.

[12] Kwon JH, Keates S, Simeonidis S, Grall F, Libermann TA, Keates AC. ESE-1, an enterocyte-specific Ets transcription factor, regulates MIP-3alpha gene expression in Caco-2 human colonic epithelial cells. J Biol Chem 2003; 278: 875-84.

[13] Rudders S, Gaspar J, Madore R, et al. ESE-1 is a novel transcriptional mediator of inflammation that interacts with NFkappa B to regulate the inducible nitric-oxide synthase gene. J Biol Chem 2001; 276: 3302-9.

[14] Eckel KL, Tentler JJ, Cappetta GJ, Diamond SE, GutierrezHartmann A. The epithelial-specific ETS transcription factor ESX/ESE-1/Elf-3 modulates breast cancer-associated gene expression. DNA Cell Biol 2003; 22: 79-94.

[15] Mysorekar IU, Mulvey MA, Hultgren SJ, Gordon JI. Molecular regulation of urothelial renewal and host defenses during infection with uropathogenic Escherichia coli. J Biol Chem 2002; 277: 74129.

[16] Neve RM, Chin K, Fridlyand J, et al. A collection of breast cancer cell lines for the study of functionally distinct cancer subtypes. Cancer Cell 2006; 10: 515-27.

[17] Chang CH, Scott GK, Kuo WL, et al. ESX: a structurally unique Ets overexpressed early during human breast tumorigenesis. Oncogene 1997; 14: 1617-22.

[18] Debnath J, Muthuswamy SK, Brugge JS. Morphogenesis and oncogenesis of MCF-10A mammary epithelial acini grown in three-dimensional basement membrane cultures. Methods 2003; 30: 256-68.

[19] Coppe JP, Itahana Y, Moore DH, Bennington JL, Desprez PY. Id-1 and Id-2 proteins as molecular markers for human prostate cancer progression. Clin Cancer Res 2004; 10: 2044-51.

[20] Irizarry RA, Bolstad BM, Collin F, Cope LM, Hobbs B, Speed TP Summaries of Affymetrix GeneChip probe level data. Nucleic Acids Res 2003; 31: e15.

[21] Smyth GK. Linear models and empirical bayes methods for assessing differential expression in microarray experiments. Stat Appl Genet Mol Biol 2004; 3: Article3. 
[22] Metzger D, Clifford J, Chiba H, Chambon P. Conditional SiteSpecific Recombination in Mammalian Cells Using a LigandDependent Chimeric Cre Recombinase. Proc Natl Acad Sci USA 1995; 92: 6991-5.

[23] Neve RM, Ylstra B, Chang CH, Albertson DG, Benz CC. ErbB2 activation of ESX gene expression. Oncogene 2002; 21: 3934-8.

[24] Thiery JP. Epithelial-mesenchymal transitions in tumour progression. Nat Rev Cancer 2002; 2: 442-54.

[25] Bargmann CI, Hung MC, Weinberg RA. Multiple independent activations of the neu oncogene by a point mutation altering the transmembrane domain of p185. Cell 1986; 45: 649-57.

[26] Bargmann CI, Weinberg RA. Increased tyrosine kinase activity associated with the protein encoded by the activated neu oncogene. Proc Natl Acad Sci USA 1988; 85: 5394-8.

[27] Bissell MJ, Radisky D. Putting tumours in context. Nat Rev Cancer 2001; 1: 46-54.

[28] Olayioye MA, Neve RM, Lane HA, Hynes NE. The ErbB signaling network: receptor heterodimerization in development and cancer. EMBO J 2000; 19: 3159-67.

[29] Worthylake R, Opresko LK, Wiley HS. ErbB-2 amplification inhibits down-regulation and induces constitutive activation of both ErbB-2 and epidermal growth factor receptors. J Biol Chem 1999; 274: 8865-74

[30] Smyth GK, Michaud J, Scott HS. Use of within-array replicate spots for assessing differential expression in microarray experiments. Bioinformatics 2005; 21: 2067-75.

[31] Brown C, Gaspar J, Pettit A, et al. ESE-1 is a novel transcriptional mediator of angiopoietin-1 expression in the setting of inflammation. J Biol Chem 2004; 279: 12794-803.

[32] Kang Y, Massague J. Epithelial-mesenchymal transitions: twist in development and metastasis. Cell 2004; 118: 277-9.

[33] Yang J, Mani SA, Donaher JL, et al. Twist, a master regulator of morphogenesis, plays an essential role in tumor metastasis. Cell 2004; 117: 927-39.

[34] Shiomi T, Okada Y. MT1-MMP and MMP-7 in invasion and metastasis of human cancers. Cancer Metastasis Rev 2003; 22: 145-52.

[35] Rangaswami H, Bulbule A, Kundu GC. Osteopontin: role in cell signaling and cancer progression. Trends Cell Biol 2006; 16: 7987.

[36] McGuire JK, Li Q, Parks WC. Matrilysin (Matrix Metalloproteinase-7) Mediates E-Cadherin Ectodomain Shedding in Injured Lung Epithelium. Am J Pathol 2003; 162: 1831-43.

[37] Le TL, Yap AS, Stow JL. Recycling of E-cadherin: a potential mechanism for regulating cadherin dynamics. J Cell Biol 1999; 146: 219-32.

[38] El-Tanani M, Platt-Higgins A, Rudland PS, Campbell FC. Ets gene PEA3 cooperates with beta-catenin-Lef-1 and c-Jun in regulation of osteopontin transcription. J Biol Chem 2004; 279: 20794-806.
[39] Agnihotri R, Crawford HC, Haro H, Matrisian LM, Havrda MC, Liaw L. Osteopontin, a novel substrate for matrix metalloproteinase-3 (stromelysin-1) and matrix metalloproteinase-7 (matrilysin). J Biol Chem 2001; 276: 28261-7.

[40] Fingleton B, Vargo-Gogola T, Crawford HC, Matrisian LM. Matrilysin [MMP-7] expression selects for cells with reduced sensitivity to apoptosis. Neoplasia 2001; 3: 459-68.

[41] Singhal H, Bautista DS, Tonkin KS, et al. Elevated plasma osteopontin in metastatic breast cancer associated with increased tumor burden and decreased survival. Clin Cancer Res 1997; 3: 605-11.

[42] Lynch CC, Crawford HC, Matrisian LM, McDonnell S. Epidermal growth factor upregulates matrix metalloproteinase-7 expression through activation of PEA3 transcription factors. Int J Oncol 2004; 24: $1565-72$.

[43] Katagiri YU, Sleeman J, Fujii H, et al. CD44 variants but not CD44s cooperate with beta1-containing integrins to permit cells to bind to osteopontin independently of arginine-glycine-aspartic acid, thereby stimulating cell motility and chemotaxis. Cancer Res 1999; 59: 219-26.

[44] Schedin PJ, Eckel-Mahan KL, McDaniel SM, et al. ESX induces transformation and functional epithelial to mesenchymal transition in MCF-12A mammary epithelial cells. Oncogene 2004; 23: 1766 79.

[45] Prescott JD, Koto KS, Singh M, Gutierrez-Hartmann A. The ETS transcription factor ESE-1 transforms MCF-12A human mammary epithelial cells via a novel cytoplasmic mechanism. Mol Cell Biol 2004; 24: 5548-64.

[46] Blick T, Widodo E, Hugo $\mathrm{H}$, et al. Epithelial mesenchymal transition traits in human breast cancer cell lines. Clin Exp Metastasis 2008; 25: 629-42.

[47] Nieto MA. The snail superfamily of zinc-finger transcription factors. Nat Rev Mol Cell Biol 2002; 3: 155-66.

[48] Mandel L, Doctor R, Bacallao R. ATP depletion: a novel method to study junctional properties in epithelial tissues. II. Internalization of $\mathrm{Na}^{+}, \mathrm{K}(+)$-ATPase and E-cadherin. J Cell Sci 1994; 107: 3315-24.

[49] Nagano O, Saya H. Mechanism and biological significance of CD44 cleavage. Cancer Sci 2004; 95: 930-5.

[50] Geyer CE, Forster J, Lindquist D, et al. Lapatinib plus capecitabine for HER2-positive advanced breast cancer. N Engl J Med 2006; 355: 2733-43.

[51] Crawford HC, Fingleton B, Gustavson MD, et al. The PEA3 subfamily of Ets transcription factors synergizes with beta- cateninLEF-1 to activate matrilysin transcription in intestinal tumors. Mol Cell Biol 2001; 21: 1370-83.

[52] Trost TM, Lausch EU, Fees SA, et al. Premature senescence is a primary fail-safe mechanism of ERBB2-driven tumorigenesis in breast carcinoma cells. Cancer Res 2005; 65: 840-9. 